\title{
Comunicación empresarial y manejo de imagen
}

\author{
Cecilia ALEGRÍA
}

Nadie discute hoy en dia la importancia de la sana preocupación que se tiene por la imagen de la empresa ante los públicos con los que ésta interactúa. Los métodos y técnicas para "cuantificar" el valor de la imagen se vuelven cada día más eficientes y sofisticados. Los empresarios y ejecutivos de alto nivel están cada vez más conscientes de que el gasto en imagen es una inversión valiosa y que a la larga reditúa beneficios claramente observables y medibles.

El tema de la imagen institucional se relaciona indefectiblemente con el de la comunicación. La comunicación es el proceso y la imagen el resultante. No es posible alcanzar una imagen óptima sin haber antes comunicado adecuadamente la identidad de una organización a sus públicos.

Para lograr este objetivo, la empresa debe confiar en un experto que tenga capacidad y conocimientos suficientes como para hacerse cargo de la transmisión sistemática de los principales conceptos y atributos de identidad a los públicos, a partir de acciones y mensajes especialmente diseñados para tal fin. Este especialista es el comunicador empresarial.

El comunicador empresarial es un estratega que pone en práctica las tácticas diseñadas para el logro de determinados objetivos comunicacionales en el marco de macropolíticas y objetivos empresariales.

No en vano se le exige al comunicador empresarial que se desempeña como gerente de Comunicaciones el mismo nivel de excelencia que al gerente de Marketing o al gerente de Recursos Humanos, ya que para la mayoría de las empresas la ubicación del primero en el organigrama expresa la 
marcada influencia que éste tiene sobre toda la organización, al depender directamente de la gerencia general.

El comunicador empresarial desempeña sus funciones en una unidad a nivel de staff, encargada de asesorar a la Gerencia General en la definición de una política integral de comunicaciones internas y externas. El éxito de ésta dependerá, en parte, de si resulta consistente con la identidad corporativa, congruente con la realidad institucional y determinada por la imagen que se desea proyectar a los públicos de la empresa.

\section{UNIDADES DE COMUNICACIÓN EMPRESARIAL}

¿Cómo se denominan las unidades organizacionales en las que se ubica el comunicador empresarial actualmente? Nombres hay para todos los gustos y visiones. Tenemos por ejemplo: Oficina de Comunicaciones, de Relaciones Corporativas, de Imagen Institucional, de Asuntos Públicos, de Relaciones Institucionales o de Asuntos Corporativos. Lo importante no es tanto cómo se llama sino lo que hacen y cómo lo hacen.

Dicha Oficina, División o Gerencia desempeña múltiples funciones valiosas entre las que cabe resaltar la de detectar y reaccionar en forma sistemática ante focos de riesgo potencial que puedan alterar la imagen de la empresa ante su público objetivo (clientes y consumidores) y ante la opinión pública.

Para esto no sólo deberá revisar la prensa diariamente sino estar al tanto de las acciones que se llevan a cabo en todas las otras áreas de la organización, reconociendo las limitaciones y carencias de cada una en un momento dado y que puedan repercutir negativamente en la percepción que el público posee del servicio.

La Oficina de Comunicación Corporativa deberá desarrollar, asimismo, una actividad constante entre la organización y sus diversos públicos, tanto internos como externos, con el fin de generar en éstos predisposiciones conductuales favorables hacia las acciones y proyectos de la institución.

Numerosos autores sostienen que una vez que una empresa logra mantener una imagen óptima y sólida a lo largo del tiempo, ocurre que los públicos le disculpan más fácilmente los pequeños errores que pudiera cometer en su servicio o con su producto. Por el contrario, señalan que si la imagen es negativa, los errores serán vistos con lupa por un cliente insatisfecho. 
El objetivo final de la unidad organizacional encargada del manejo de la comunicación empresarial podría resumirse como sigue: transmitir adecuadamente la identidad institucional a los públicos y clientes de la empresa, a través de acciones y soportes de comunicación (masivos y especializados) expresamente seleccionados con el fin de obtener un determinado posicionamiento de imagen en el medio.

La imagen óptima no se puede lograr si aquello que se comunica no coincide con los mensajes que se emiten desde el plano de la "realidad institucional". Esto implica reconocer que no hay imagen que pueda construirse sobre bases poco sólidas, sobre mentiras o falsas presunciones. Como el castillo de naipes, esta imagen se derrumbará ante el primer soplo de una realidad que el cliente constatará, empíricamente, que verá, oirá o palpará con toda nitidez. De lo que se deduce que si el producto o servicio es malo o mediocre, no hay campaña publicitaria que lo salve. Más bien como resultante del efecto boomerang, puede ser considerado un fraude.

Una vez que la empresa tiene asegurada, aunque sea en parte, la calidad de su servicio y producto, no puede darse el lujo de menospreciar el rol de las comunicaciones con el fin de posicionarse en el medio y consolidar una imagen acorde con sus pretensiones

Para alcanzar esto último no basta con preguntarse cómo es que uno desea que lo vean hoy, sino que también es fundamental inquirirse acerca de cómo espera ser visto en el largo plazo.

\section{ALGUNAS PRECISIONES SOBRE LA IDENTIDAD}

Plantearse el tema de la identidad es imprescindible cuando de abordar la imagen se trata. Porque identidad e imagen son como las dos caras de una misma moneda. No existe imagen alguna sin identidad previa. ¿Cómo podemos pretender que los demás nos perciban de determinada manera si ni siquiera nosotros mismos tenemos idea de cómo queremos ser percibidos? ¿Cuáles son los principales rasgos que definen nuestra personalidad y que deberian ser conocidos por el otro? Así como el ser humano se plantea preguntas existenciales en determinado momento de su vida, así también la empresa debe reflexionar sobre su autorrepresentación, de preferencia desde su nacimiento mismo, desde su creación u origen. 
Las respuestas que la empresa se brinde a sí misma se constituirán en una base sólida para la generación paulatina de una cultura organizacional. Porque la determinación de un texto básico de identidad hará más perceptible, comprensible y asimilable nuestro discurso. Y si el discurso es bien captado por los clientes internos, puede que así también lo sea por los externos.

Este texto básico recogerá dos grandes planos de definición institucional: los conceptos y los atributos.

\section{CONCEPTOS Y ATRIBUTOS DE IDENTIDAD}

Entenderemos por concepto aquel factor constitutivo de la identidad que, como representación simbólica de una idea abstracta y general, concede estabilidad y permanencia en el tiempo. Resulta dificil de modificar en cuanto justifica y legitima la esencia o razón de ser de la empresa.

Por ejemplo, el concepto más genérico de un banco es "institución financiera con fines de lucro". Si éste se modificase, la empresa simplemente dejaría de ser un banco.

Otro concepto que define la identidad bancaria es "administración responsable de recursos de terceros". No hay banco que no se autorrepresente de esta manera.

También hay conceptos específicos que algunas instituciones pueden recoger y otras no porque corresponden a una definición más fina y particular de aquellos elementos de su identidad que realmente la distinguen de las demás.

Por ejemplo, puede que un banco se diferencie de otro por su "calidad de marca", por el status que brinda a su cuentacorrentista al mostrar una chequera o tarjeta de crédito que lo identifica como uno de sus exclusivos clientes. Este es un concepto específico que no todo los bancos comparten.

Así, el texto básico de identidad se configura sobre la base de conceptos genéricos y específicos. Lo mismo ocurre con los atributos, también pueden ser de ambas clases: generales y particulares. Es en la determinación estudiada de estos últimos donde la empresa encuentra el camino para el posicionamiento estratégico.

El atributo de identidad es la característica o cualidad de la organización que representa mejor al concepto en una determinada coyuntura. El atributo es modificable, varía con el tiempo. Se halla mucho más a expensas de los cambios en el contexto. Representa la parte voluble de la identidad, porque dado que la empresa es un sistema abierto, es proclive a las transformaciones. 
Mientras que los conceptos responden a la pregunta “¿quiénes somos?”, los atributos describen el "cómo somos”, y por tanto son mucho más fáciles de reconocer, a nivel de imagen, que los conceptos.

Por ejemplo, se dice que un banco es "confiable", "eficiente", "moderno". Estas son características que el cliente puede comprobar de manera muy práctica y cotidiana, más aún cuando aplicando un criterio comparativo (dado que casi todos los bancos se autorrepresentan de esta manera) puede discernir cuáles lo son más y cuáles lo son menos. Por ende, resulta preferible que un banco preste muchísima atención a sus "atributos específicos" y los desarrolle en grado sumo, en vez de estar gastando recursos y energias en potenciar aquellos "genéricos" en los que la competencia le puede llevar considerable ventaja.

Toda organización debe reincidir en la práctica periódica de análisis y revaloración de su "discurso de identidad".

Se da por descartado que no hay organización a estas alturas del siglo XX que no cuente con una misión, una visión o valores organizacionales claramente estipulados que guíen su accionar.

La persecución de metas elevadas brinda un sentido teleológico al quehacer organizacional. De allí que la declaración del "deber ser" sustente la realización del ser.

La textualización de la identidad se condensa en dos grandes preguntas:

- ¿Quiénes decimos que somos?

- ¿Quiénes decimos que queremos ser?

En la medida en que la primera pregunta se halle respaldada por la realidad, es decir en tanto que la identidad corporativa se plasme en la realidad institucional, nuestras posibilidades de alcanzar una imagen exitosa serán mucho mayores. Asimismo, una identidad bien definida e idealizada se presenta como el mejor estímulo para la optimización de la realidad de la empresa.

"Me reconozco como soy en la utopía de lo que estoy llamado a ser" es una frase que sintetiza la dialéctica empresarial entre la realidad y la autorrepresentación.

"Lo que soy en función de lo que seré" resume la vocación por el mejoramiento continuo y el logro de la excelencia de las empresas modernas.

Tanto la configuración y consolidación de la identidad, como la tendencia de la realidad institucional a acercarse al modelo propuesto desde la autorepresentación, resultan elementos vitales para el logro de la homeostasis de la organización. Como dirán Mintzberg, Galbraith y Weick: "Las orga- 
nizaciones son colectividades cuyos participantes comparten un interés como en la supervivencia del sistema y están unidos en actividades colectivas formal e informalmente estructuradas para tal fin".

Uno de los requisitos para la obtención del equilibrio y la reproducción del sistema reside en la adecuación de la realidad a la identidad, en la medida en que mientras más tendamos a ser en la praxis lo que aspiramos a ser idealmente, nuestra imagen se orientará hacia la excelencia.

El texto básico de identidad se completa acogiendo la perspectiva de los públicos en las grandes definiciones. De alli que debamos agregar las inquietudes:

- ¿Qué queremos que nuestros públicos crean que somos?

- ¿Qué queremos que nuestros públicos crean que debemos ser?

Y aunque la pregunta aparezca planteada en primera persona, no sólo se trata de satisfacer nuestras propias expectativas, sino fundamentalmente las ajenas, las de aquéllos a quienes vendemos un bien o servicio, las de aquéllos con quienes nos relacionamos en nuestro diario quehacer organizacional. Expectativas que se forman en el aquí y el ahora de cara a un mañana.

En sintesis, entendemos la identidad institucional como el conjunto de conceptos y atributos, asumidos como propios por la institución, que configuran un discurso a ser comunicado a los públicos, con el objeto de alcanzar la legitimación de la empresa ante éstos en una determinada coyuntura.

Los valores "textualizados" en la identidad se construyen y comparten en la cultura corporativa. Los elementos de la identidad, los conceptos, valores y atributos que la configuran se evidencian en la cultura en la medida en que se viven y experimentan empíricamente, legitimándose y reproduciéndose.

Según Allaire y Firsirotu, las organizaciones son gestoras de "procesos de socialización", dotadas de normas y estructuras, capaces de generar valores, creencias y significados compartidos. Muy conocida es la definición que propone Schein de la cultura organizacional como el "patrón de presunciones básicas que un grupo dado ha inventado, descubierto o desarrollado durante su aprendizaje para manejar sus problemas de adaptación externa e integración interna”.

Ahora bien, para que el proceso de adaptación se vea facilitado y promovido se hace indispensable una "identidad institucional" diseñada por los gestores de la organización, difundida eficientemente por los comunicadores empresa- 
riales al servicio de ésta y conocida por todos y cada uno de los miembros de la institución.

No se puede vivir aquello que no se conoce. Pues si bien es cierto -sostienen Peters y Waterman-que los valores que conforman la cultura generalmente están implícitos en la organización, la posibilidad de explicitarlos y comunicarlos adecuadamente al público interno es una poderosa herramienta de integración en manos del comunicador empresarial.

Una vez explicitado el discurso de identidad institucional, corresponde a la unidad encargada de las comunicaciones el definir a través de qué medios y acciones éste va a ser difundido. No basta con precisar lo que somos y seremos. Hay que comunicarlo y esforzarnos por ponerlo en práctica.

\section{LA COMUNICACIÓN INSTITUCIONAL SISTÉMICA}

Para transmitir la identidad corporativa de la mejor manera posible a los públicos de la organización, la práctica comunicacional debe ser entendida de manera sistémica.

No hay un medio, no hay una acción, no hay un mensaje que importe más que otros.

Todos se refuerzan, todos se complementan, todos se funden en un mismo aliento comunicativo destinado, entre otros fines, a la optimización de la imagen.

Por otra parte, si una de las acciones falla, si uno de los mensajes porta errores en sí mismo o en el medio que lo transmite, el hecho repercute sobre todo el sistema comunicacional, desbalancéandolo, modificando su estado. De allí que sea tan importante la estrategia y que las tácticas también deban ser concienzudamente pensadas y elegidas.

El principio de sinergia se plasma muy bien en el comportamiento normal de una organización equilibrada. Ciertamente, el todo es mucho más que la mera sumatoria de las partes. El accionar aislado de uno de los departamentos no tiene sentido. La unidad que no se relaciona con las otras se condena a sí misma al fracaso y conducirá a la empresa por el mismo camino.

Myers y Myers nos recuerdan que "una organización existe porque uniendo recursos los individuos pueden lograr más cosas juntos de lo que podrian en forma individual".

Conforme al principio de reciprocidad de la Teoría de Sistemas, si las acciones de algunos elementos de la organi- 
zación no afectaran a los demás, entonces no se les podría incluir como parte del conjunto de componentes necesarios para el funcionamiento de ese sistema. Así, las interacciones e interdependencias entre los subsistemas son tan o más importantes que los componentes individuales (Edgar Huse y B. James).

Además, los sistemas presentan un principio básico, el de la "equifinalidad" que también resulta aplicable a la comunicación empresarial. Como bien apunta Gonzalo Molina, se entiende por equifinalidad la búsqueda de los mismos objetivos finales por todos los elementos del sistema, con un amplio nivel de negociación en lo que respecta a la fijación de los objetivos particulares de cada función, y con gran autonomía en cuanto a la determinación de los medios que se deben seguir para conseguirlos.

Los principales fines de la comunicación empresarial podrian resumirse de la siguiente manera:

- Transacción de información entre los elementos del sistema y del sistema con su medio.

- Interacción destinada al mutuo conocimiento y la integración entre los componentes del todo.

- Generación de conductas reciprocas de beneficio entre la organización y su medio.

- Retroalimentación para el mantenimiento del sistema y el logro de las metas institucionales.

- Retroalimentación para la armonización de las expectativas y los intereses de la organización con aquéllos de sus públicos (internos y externos).

- Transmisión adecuada de la identidad institucional a los públicos para la obtención de un determinado posicionamiento de imagen.

Otra característica de los sistemas y de los procesos es la dinámica entre los componentes del todo. Esta dinámica se torna fácilmente reconocible en el proceso comunicativo de las empresas.

La dinámica del sistema comunicacional implica el ajuste reciproco de las acciones, medios y mensajes que, asî como se apoyan y enriquecen si están bien seleccionados, se entorpecen y anulan mutuamente si nacieron disociados. Por esto resulta vital "armar el esqueleto" sobre el cual se va a vertebrar el ejercicio profesional del comunicador empresarial en un lapso determinado.

Así, el Plan Estratégico de Comunicaciones debe presentarse como un todo perfectamente ensamblado. Una acción, en sí misma, pierde sentido fuera del todo. Una acción, contemplada como parte aislada, independiente y autónoma, 
no reviste mayor valor para la empresa. Es en su interrelación con otras, donde la acción justifica su razón de ser $\mathrm{y}$ adquiere legitimidad.

Para poder elegir adecuadamente aquellas acciones, medios y mensajes que se constituyan en los mejores portadores de la identidad institucional debemos volver al punto de partida y preguntarnos: ¿Qué conceptos y atributos de identidad desea y debe transmitir la organización en el corto plazo? (Los planes o programas suelen trazarse para uno, tres o cinco años de duración). Una vez que esta pregunta haya sido cabalmente resuelta recién será factible determinar las estrategias y tácticas a emplear para el cumplimiento de los objetivos trazados.

Uno de los grandes problemas de las empresas que no reconocen aún la importancia de revisar de manera constante sus acciones, a la luz de los conceptos y atributos que pretenden proyectar, se resume en la desarticulación de sus actividades y mensajes. Como no precisan a dónde apuntan, eligen hacer aquello que no necesitan y dejan de hacer lo que precisan. De esta forma se produce el desperfilamiento del discurso de identidad.

Al público le llegan tantos estímulos, tantos mensajes, tantos y tan diversos atributos provenientes de una misma compañía que finalmente esto se traduce en confusión y falta de claridad conceptual. A su vez, este desconocimiento de lo que la empresa es y hace en esencia, conduce al surgimiento de una imagen distorsionada que evidentemente perjudica la relación organización/cliente y organización/opinión pública.

Tan perjudicial es la indefinición, confusión y dispersión de los conceptos y atributos de identidad como la falta de una adecuada jerarquización en el nivel de la autorrepresentación. Pues si bien una empresa puede describirse a sí misma utilizando decenas de adjetivos calificativos, no pretenderá que los públicos perciban con claridad todos esos atributos al mismo tiempo. Deberá privilegiar y otorgar un orden al conjunto. Por eso, un atributo que por meses estuvo relegado a un segundo o tercer plano puede pasar a ocupar el primero de un momento a otro. Depende de la estrategia. Así también, si las circunstancias lo ameritan, un atributo puede ser desplazado a la lista de espera. Como, por ejemplo, cuando en épocas de crisis económica y austeridad, el atributo de "rentabilidad" de un banco es suplantado por el de "responsabilidad social".

$\mathrm{Y}$ aunque el banco siga siendo un negocio muy lucrativo para algunos, no lo anda pregonando a voz en cuello. 
Prefiere en esa coyuntura mostrarse "comprometido" con los dificiles momentos por los que atraviesa el país y realizar acciones en favor de la ecología, la educación o la niñez.

En cuanto al manejo de los medios, acciones y mensajes de comunicación empresarial, la mayoría de las empresas adolecen de los siguientes defectos:

- Privilegian la publicidad masiva orientada a la venta de productos, en desmedro de las campañas institucionales destinadas a proyectar la identidad corporativa.

- Carecen de medios especializados orientados hacia la proyección institucional.

- No valoran lo suficiente la necesidad de contar con una política de transmisión de identidad, a partir de eventos y acciones coherentes entre sí, que favorezcan un claro reconocimiento de los atributos de la organización por los públicos.

\section{EL SISTEMA DEL ENTORNO Y EL SISTEMA DE LAS ACTUACIONES}

A todo lo anterior debemos agregar la falta de conciencia sobre aquellos factores que, aunque no tienen como fin primero comunicar la identidad, sin embargo la transmiten, y en ocasiones de manera más que elocuente. Por ejemplo, el ámbito que Norberto Chávez en su libro Imagen corporativa define como "sistema del entorno": la arquitectura de la sede central y las agencias, su ubicación en un barrio, el mobiliario, la decoración, los colores de la pintura de fachada e interiores, la limpieza de las paredes, la limpieza de los pisos, el orden o el desorden de los ambientes, la presencia o ausencia de señalética, etc.

Mayor importancia se le brinda, en el medio empresarial, a los factores más reconocibles de la identidad visual como isotipo, logotipo, colores institucionales, manual corporativo, uniformes, etc. Y últimamente se habla y predica profusamente sobre el cuidado que se ha de tener con el personal de contacto con público, al que se selecciona, capacita y evalúa con especial esmero. Es cierto que, a través de estos empleados, el cliente entra en contacto directo con la empresa y que depende en gran medida de la calidad de la atención recibida, que su impresión primera -anterior al encuentrose mantenga o se modifique. Pero no es menos cierto que, desde la perspectiva sistémica que asumimos como válida, un solo factor no basta para configurar la imagen, sino que 
ésta se plasma como resultante de la interacción dinámica entre un cúmulo de factores mutuamente dependientes. Por ende, los esfuerzos de mejora organizacional no se pueden centralizar o focalizar en un solo factor sino que deberán abarcarlos o incorporarlos a todos por igual.

$\mathrm{Y}$ hay un aspecto que se suele descuidar sobremanera, dentro de esta perspectiva sistémica de la comunicación empresarial, porque pasa inadvertido para la mayoría. Se trata del nivel de la comunicación interpersonal no verbal. ¿Qué ocurre con el cliente que acude a las oficinas de la empresa y es tratado educadamente con un "por favor", "gracias" y "hasta luego" acompañados de una cara larga, un gesto adusto y una sonrisa prefabricada que no inspira la más mínima confianza? El efecto de conjunto falla porque en el sistema uno de los elementos actúa equivocadamente y por ende influye sobre el resto.

Lo mismo sucede con el trato que las telefonistas brindan al público, el que se lleva una pésima imagen de la organización cuando la que debe comportarse como una eficiente funcionaria lo atiende apresurada y de manera poco cordial.

Así, la comunicación es un sistema abierto porque está conformado por un conjunto de componentes estrechamente relacionados entre sí, con un fin común: el intercambio de mensajes retroalimentados.

Sin retroalimentación no hay comunicación. Es una verdad indiscutible que todas las empresas deberian conocer y asumir a cabalidad.

\section{EL OBJETO DE LA COMUNICACIÓN EMPRESARIAL}

Una de las funciones esenciales de la comunicación empresarial consiste en asegurar que los mensajes transmitidos por determinados medios a los distintos públicos estén altamente vinculados con la imagen que la organización desea proyectar, la que a su vez pretenderá ser lo más afin y congruente posible con la identidad de la organización.

En orden a estos objetivos resulta fundamental realizar en forma periódica un diagnóstico muy riguroso sobre la percepción que tienen los públicos (internos y externos) acerca de los conceptos y atributos de identidad, con el fin de compararlos con aquéllos que la organización desea difundir intencionalmente. Esto deviene indispensable antes de elaborar los "mensajes de identidad", los cuales estarán basados en los conceptos y atributos específicos, adecuadamente jerarquizados, que la organización y los comuni- 
cadores que laboran en ella consideran necesario o prioritario transmitir a determinados públicos en una determinada coyuntura.

Como fruto de una buena investigación de mercado, se visualizará mejor la problemática de imagen. Se descubrirá si los conceptos y atributos de imagen son coincidentes o divergentes con los conceptos y atributos de identidad. A través de métodos y técnicas cuantitativos y cualitativos, el comunicador conocerá mejor la percepción que los clientes tienen de su servicio, de su producto y de la identidad de su empresa. Y sólo a partir de esta confrontación se hallará capacitado para elaborar los mensajes y elegir los medios, no sólo en función de determinados objetivos institucionales, sino sobre todo en función de la imagen que tienen los públicos de la organización, imagen que deberá ser mantenida, reforzada, mejorada o modificada. De allí que sea de tanta relevancia adoptar la perspectiva de los públicos de la organización, practicando la empatía.

Desde un enfoque más centrado en el receptor que en el emisor, proponemos el siguiente modelo verbal, que consta de quince pasos:

\section{Modelo de comunicación empresarial centrado en los públicos}

\section{Descripción}

\section{Componentes del modelo}

1. Un público

$\mathrm{P}=\mathrm{R}$ ( receptor )

2. Percibe a una organización

$\mathrm{O}=\mathrm{E}$ (emisor)

3. A partir de la imagen que se ha formado de ella

$\mathrm{IM}=$ imagen

4. Constituida por determinados conceptos y atributos de imagen de tal manera que

(CAIM)

5. Podrá responder EIM = efectos de imagen

6. En una situación específica

(Contexto)

7. De una cierta forma (Tipo de efecto)

8. Al recibir un tipo de contenido CAID = conceptos $y$ atrib. de ident.

9. Bajo un determinado estilo (Tratamiento)

10. De uno o más mensajes MID = mensajes de identidad

11. Transmitidos a través de medios expresamente seleccionados

(MED)

12. Por encodificadores especializados $\mathrm{CE}=$ comunicador empresarial 
13. Para lograr objetivos específicos acordes con los objetivos institucionales $(\mathrm{OE})-(\mathrm{OI})$

14. De acuerdo con necesidades e intereses coyunturales y/o estructurales

(Prioridades)

15. Que se gestan a partir de la identidad de la organización $\quad$ ID = identidad

La explicación del modelo se sintetiza como sigue:

Una organización dada, poseedora de conceptos y atributos que configuran su identidad, requiere de la intervención de un comunicador empresarial, el cual teniendo conocimiento de los objetivos institucionales y de acuerdo con determinados objetivos específicos vinculados con necesidades e intereses coyunturales y estructurales (prioridades), planifique, programe y ejecute mensajes de identidad (MID) dirigidos a los públicos específicos de la organización a través de medios expresamente seleccionados (MED).

Los MID privilegiarán el tipo de contenido que la organización haya decidido dar a conocer sobre la base de la necesaria proyección de los CAID (conceptos y atributos de identidad) mediante un cuidadoso tratamiento que privilegiará el estilo que mejor se adecúe al público-objetivo.

La conveniente elección de los M1D y de los MED producirá un tipo de efecto (racional, emotivo o de modificación de opinión) que posibilitará que los CAIM (conceptos y atributos de imagen) que los públicos específicos (PE) tengan de la organización $(\mathrm{O})$, resulten semejantes o idénticos a los CAID que ésta requería proyectar.

El comunicador empresarial analiza y controla los EIM (efectos de imagen) contribuyendo a que la organización cuente con la evaluación de los mismos, lo que le permitirá seguir avanzando en el proceso de modificación, mantenimiento o reforzamiento de la imagen institucional. 
Modelo completo de comunicación entre la organización y sus públicos

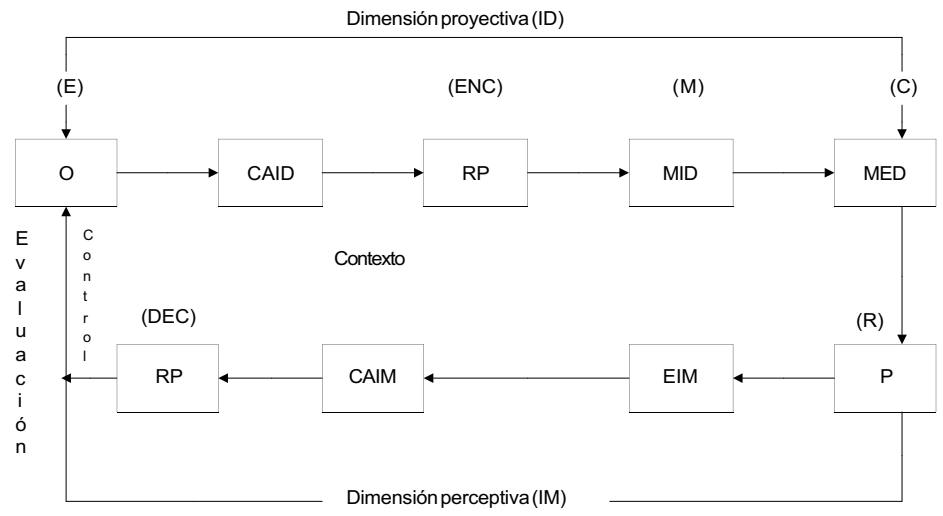

Una organización (E) caracterizada por determinados conceptos y atributos que constituyen su identidad (CAID), su manera peculiar de ser que la distingue de las demás, requiere de la mediación de encodificadores altamente especializados (ENC), los comunicadores empresariales, quienes emplearán los códigos más adecuados para alcanzar satisfactoriamente los diversos públicos de la empresa (PE).

Los comunicadores empresariales son los llamados a definir los tipos de mensajes (con sus respectivos códigos, tratamientos y contenidos específicos) que habrán de plasmarse en acciones concretas para, a través de los medios más idóneos, llegar a cada público de la manera más conveniente.

El conjunto de MID y MED empleados por el comunicador empresarial, en función de determinados objetivos para llegar a determinados públicos conforman el Plan Estratégico de Comunicaciones.

\section{EL ROL DE INTÉRPRETE DEL COMUNICADOR EMPRESARIAL}

Si bien el comunicador empresarial puede desempeñar una multiplicidad de roles, dependiendo del tipo de organización y sus circunstancias, el de "intérprete de la dinámica de las representaciones" lo faculta mejor que ningún otro para comprender la dicotomía identidad-imagen, contribuyendo a esclarecer ante la organización y sus públicos las variantes de esta relación. 
El rol de intérprete está conformado por dos tipos de acciones comunicativas: la encodificación y la decodificación. El comunicador empresarial es el encodificador de los conceptos y atributos de identidad que la organización precisa dar a conocer a sus públicos, y es el decodificador de los conceptos y atributos de imagen que los públicos poseen en relación con la empresa.

Si bien frente a los públicos y a la organización el comunicador desempeña ambos roles simultáneamente, sostenemos que es más preciso afirmar que como encodificador el comunicador presenta a los públicos los conceptos y atributos de manera tal que sean comprendidos y asimilados adecuadamente para su progresiva internalización. En consecuencia, la acción del comunicador empresarial influye sobre la configuración de los conceptos y atributos de imagen de acuerdo con los objetivos previamente trazados.

Como decodificador, por otro lado, el comunicador empresarial se ocupa de traducir la percepción que tienen los públicos acerca de los conceptos y atributos de identidad, de manera tal que la organización pueda evaluar los avances realizados en la consecución de sus objetivos de imagen.

Complementando lo explicado hasta aquí podríamos tratar de precisar aún más el rol de intérprete en sus dos aspectos.

\section{El comunicador empresarial como encodificador}

El comunicador empresarial como encodificador recoge los conceptos y atributos de identidad expresamente seleccionados con el fin de ser comunicados a los distintos públicos.

Él es quien diseña el Plan de Comunicaciones, elaborando mensajes de identidad y planificando acciones portadoras de dichos mensajes, con el objeto de lograr transmitir convenientemente la identidad institucional y lograr un determinado posicionamiento de imagen.

Además, dispone de códigos, les asigna significados y los emplea adecuadamente de acuerdo con los objetivos y estrategias de comunicación.

\section{El comunicador empresarial como decodificador}

Éste recibe el influjo de los diversos públicos, recolectando y analizando información.

Realiza un estudio comparativo y un balance entre el estado de los conceptos y los atributos de imagen, y los con- 
ceptos y atributos de identidad que la organización decidió proyectar, estableciendo coincidencias, diferencias y divergencias.

Interpreta y dota de sentido a la información recibida para facilitar a la organización el acceso a ésta y la consiguiente toma de decisiones.

Debemos dejar en claro que aunque aquí se expone que estudiamos por separado el rol de intérprete del comunicador empresarial, es sólo por un afán didáctico de esclarecimiento y simplificación, pues reconocemos que la comunicación es un proceso esencialmente dinámico donde los individuos están ocupados en enviar y recibir mensajes al mismo tiempo, para lo cual encodifican y decodifican simultáneamente afectándose uno a otro.

En suma, el rol de intérprete faculta al comunicador empresarial para constituirse en el interlocutor válido entre la identidad y la imagen de la organización.

Sólo nos queda agregar que en las organizaciones es el comunicador empresarial quien se encuentra mejor preparado para asumir este papel, lo que le compete como responsabilidad fundamental.

\section{CONCLUSIÓN}

El ejercicio profesional de la comunicación es altamente funcional para la empresa y de éste depende, en parte, los resultados en materia de imagen.

Tal desempeño consiste en el adecuado empleo de las comunicaciones, internas y externas, a partir de la determinación de políticas de imagen corporativa, su planificación estratégica, la ejecución de tácticas y la evaluación permanente no sólo de las propias acciones sino también de la percepción que los distintos públicos poseen de la empresa.

La idoneidad del comunicador empresarial será mayor en la medida en que el dominio de su especialidad se lo permita. De alli la urgencia de ordenar y sistematizar cuerpos dispersos de conocimiento para que la teoría de la comunicación empresarial respalde cada vez más y mejor a quienes la practican. 
Bibliografía

Huse, Edgard F. 1976

El comportamiento humano en las organizaciones. Bogotá: Fondo Educativo Interamericano.

Mintzberg, Henry 1993

El proceso estratégico, conceptos, contextos y casos. 2a. edición. México: Prentice Hall Hispanoamericana.

Peter, Thomas [y] Robert Waterman 1984

En busca de la excelencia. Bogotá: Editorial Norma S.A.

Schein, Edgar H. 1982

Psicología de la organización. Madrid: Editorial Prentice Hall International.

Weick, Karl E. 1982

Psicología social del proceso de la organización. México: Fondo Educativo Interamericano. 